\title{
A Cross-cultural Study of Complaint Strategies by Chinese and British University Students
}

\author{
He Yang ${ }^{1,2}$ \\ ${ }^{1}$ School of Foreign Languages and Cultures, Xiamen University, Xiamen 361005, China \\ ${ }^{2}$ School of Language and Literature, University of Aberdeen, Aberdeen AB24 3UB, UK \\ yanghe@xmu.edu.cn
}

Keywords: Complaint strategies; cross cultural pragmatics; speech acts; politeness

\begin{abstract}
Since we live in a world in which unexpected and unreasonable things occur from time to time, people complain in various settings in divergent forms every day. However, complaining has been a rather under-researched speech act in cross cultural pragmatics [1, 2, 3]. Very little is known about the similarities and differences in the choices of complaint strategy and realization patterns of the act made by native speakers of Chinese and of British English. This study investigates the complaint strategies by Chinese university students and their British counterparts. Thirty Chinese students and thirty British students participated in the study. The data were elicited through Background Questionnaire and Discourse Completion Tests (DCT). The overall findings of the current study indicate that there were mainly similarities in the pragmatic behaviour of the native and non native speakers who participated in the research project, with a few minor differences.
\end{abstract}

\section{Introduction}

A complaint is usually determined by a highly emotional situation in which it is hard for the speaker to keep control over the words uttered and remain tactful. As native speakers, language learners may easily find themselves in a situation in which they need to express their negative feelings towards an event or a person's action, therefore it is crucial for them to know when it is acceptable to complain and how to complain in a polite way in order to avoid negative reactions from the interlocutors, but while being effective at the same time.

This paper aimed at answering the following research questions:

1) How do Chinese speakers of English L2 complain in English? What strategies do they use to complain?

2) How do L2 English speaking norms compare to the norms of L1 English?

\section{Literature Review}

\subsection{Speech Act Theory}

Speech Act Theory is usually attributed to the British philosopher J.L.Austin [4]. Austin's ideas were refined, systematized, and advanced by his student, the American philosopher John R. Searle. He defined speech acts as 'the smallest units of rule-governed meaningful communication' [5]. Simply stated, the central tenet of speech act theory is that the uttering of a sentence is an action, saying is (part of) doing, or words are (part of) deeds. They can be issued, for example, to make requests, offers, and promises, to offer apologies, to give commands and so on, and can be analyzed on three levels: locutionary, illocutionary and perlocutionary. Searle proposed five macro categories in which speech acts can be classified into declaratives, representatives, expressives, directives and commissives.

Speech acts indeed are a dynamic and interactive process, rather than a static product. As Thomas observes 'making meaning is a dynamic process involving the negotiation of meaning between speaker and hearer, the context of utterance and the meaning potential of an utterance [6].

\subsection{Politeness}

Politeness research was introduced into linguistics more than thirty years ago and since then it has experienced an explosion of interest: a great deal of empirical studies have investigated, both individually and cross culturally, its realizations in many different languages. 
Among the various accounts of politeness as a pragmatic phenomenon Leech's Politeness Principle sees politeness as crucial in explaining the indirectness often used by people in conveying certain expressions [7]. A more comprehensive approach to linguistic politeness was taken by Brown and Levinson [8]; they argued that the potential illocutionary force of certain speech acts and supported their work with cross cultural empirical evidence. Central in their view is the concept of 'face', corresponding to the notion of public self-image, which can be positive when it refers to the need to be approved of or negative when it refers to the need to be independent and not imposed on by others. When interacting, a speaker can modulate the illocutionary force of the words uttered by rationally opting for a strategy that threatens the interlocutor's face in what is termed as a 'facethreatening act' (FTA).

Both Leech's and Brown and Levinson's views of politeness drew on speech act theory, as we have seen, and were influenced by Grice's Cooperative Principle and his four maxims of quantity, quality, relation and manner which are thought to govern any exchange [9].

\subsection{Previous Studies on Complaints}

The speech act of complaining falls into the category of what Searle termed 'expressive acts': when issuing a complaint the speaker expresses displeasure or annoyance as a reaction to a past or ongoing action. Indirect complaints are defined by Boxer as 'the expression of dissatisfaction to an interlocutor about oneself or someone/something that is not present' [10]. Conversely, direct complaints are addressed to the person who is held responsible for a perceived offence, therefore they are potentially high face-threatening acts in that they threaten both the speaker's and the interlocutor's face; they are socially delicate and require a sophisticated communicative competence. Ultimately they can be challenging not only for advanced learners, but also for native speakers of English who often pre-plan how they will go about making a complaint. Indeed research indicates that complaints are complex and often require many turns to be completed.

Olshtain and Weinbach compared complaint realizations by advanced learners of Hebrew to native speakers' performances and to English L1 productions [11]. They identified five strategies with different degrees of severity and their study indicates that the native speakers tend to cluster around the strategies with a medium degree of severity, avoiding both the less and more severe ones. This is strongly correlated to the social status of the hearer: the lower the status, the stronger the tendency to more severe realizations. The non native speakers produced longer complaints and tended to use more softeners, but also more intensifiers.

Trosborg examined the development of pragmatic competence in requesting, complaining and apologizing by Danish learners of English [12]. She analyzed the realization strategies, directness levels employed in the illocutions mentioned and the types of moves (initiating moves, responding moves, follow up moves) used. She concluded that L2learners produced fewer complaints than native speakers and their performances differed also in terms of directness and of effectiveness and they showed a tendency to give up easily when faced with resistance from the accused. Therefore their performances were less convincing and overall they appeared as 'weak complainers'.

Murphy and Neu analysed contrastively the productions of American native speakers and Korean learners of English [13]. In their work the features of the non native complaints were investigated also from the addressee's point of view, in order to find out whether they were socially appropriate. The learners were found to produce more criticism than complaints, which was considered socially unacceptable by the native speakers who rated the non native productions according to their acceptability.

In Tanck's study native speakers of American English and non native speakers of English with different linguistic background produced the same speech act set components but with a different quality [14]. Precisely the non native speakers provided answers which were linguistically correct but sometimes too direct or even containing an emotional plea, which did not allow them to be well received by the native speakers.

In summary, pragmatic failure concerning complaints can be ascribed to the learners' excessive directness and aggressiveness, which might be caused by L1 transfer, cultural differences and also individual differences. 


\section{Methodology}

\subsection{Participants}

A total of 60 university students participated in this study: 30 Chinese university students and 30 British university students. The Chinese students had neither lived in an English speaking country before taking part in this study nor received any specific instruction in pragmatics before or during this study. The age of Chinese students ranged from 21 to 32, with an average age of 23.91; the age of British university students ranged from 19 to 29, with an average age of 23.04. All the participants came from diversified majors. Moreover, all Chinese students involved in this study had passed the CET Band-6 exams, so their English proficiency could be considered as intermediate advanced level.

\subsection{Instruments}

According to Roever, the most commonly used research instruments in the field of cross culture pragmatics or interlanguage pragmatics are: Discourse Completion Tasks (DCTs), role plays, metapragmatic judgments and multiple choice instruments [15]. Although the collection of authentic interactions would have provided a wealth of information, it was not employed because of the low probability of collecting a sufficient number of examples of complaining strategies. DCTs allow rapid and targeted collection of a large amount of data and are powerful in 'capturing the canonical shape of speech acts' [16].

\subsection{Procedures}

A complaint is very complex; it can be made up of different components and can require many turns to be completed. The interlocutors' reactions can give the interaction possible different outcomes, as shown in Fig.1.

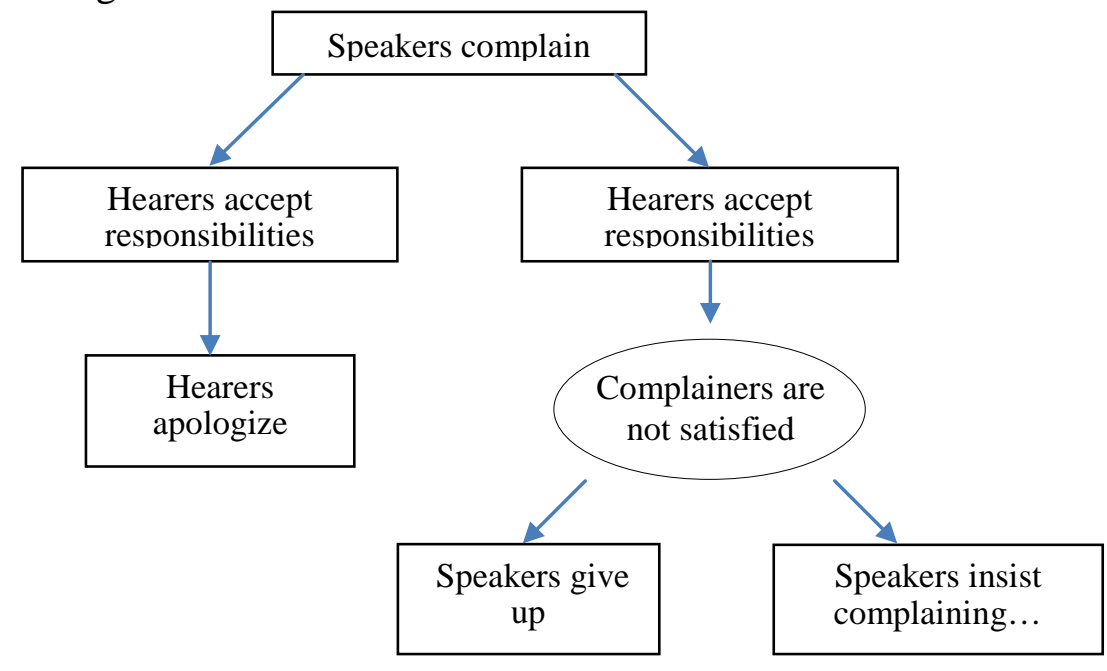

\subsection{Data Analysis}

Fig. 1 The flow chart of complaining

The first step of the coding phase was that of identifying the strategies employed by the participants when complaining. This study adopted Trosborg's taxonomy of complaints. I made a distinction between what can be considered core complaint strategies used by the speaker to express their feelings towards a past event and the supportive moves which are used precisely to support either justifying, preparing or mitigating- the act of complaining.

\section{Findings and Discussions}

The overall findings of the current study indicate that there were mainly similarities in the pragmatic behaviour of the native and non native speakers who participated in the research project, with a few minor differences.

The following tables contain the raw number of occurrences for each strategy, supportive move or direct act in the corpus of data collected for the study, and the percentage within the total of occurrences, for both non native speakers and native speakers. 
Table 1 NS's and NNS's complaining strategies

\begin{tabular}{clllll}
\hline Category & \multicolumn{1}{c}{ Strategy } & \multicolumn{2}{c}{ NS } & \multicolumn{2}{c}{ NNS } \\
\hline Opting out & Below the level of reproach & 2 & $7 \%$ & 7 & $15 \%$ \\
\hline \multirow{2}{*}{ Category 1} & Hints & 0 & $0 \%$ & 0 & $0 \%$ \\
& Deplorable situation & 17 & $59 \%$ & 26 & $57 \%$ \\
& Annoyance & 3 & $10 \%$ & 6 & $13 \%$ \\
\hline \multirow{2}{*}{ Category 2 } & Accusation & 3 & $10 \%$ & 5 & $11 \%$ \\
& Modified blame & 4 & $14 \%$ & 2 & $4 \%$ \\
\hline Category 3 & Criticism & 0 & $0 \%$ & 0 & $0 \%$ \\
\hline & Total & 29 & $100 \%$ & 46 & $100 \%$ \\
\hline
\end{tabular}

The cross cultural pragmatics analysis in the present study shows that NS and NNS made different choices in their complaints at the structural and linguistic levels in terms of socio-cultural constraints. Chinese learners of English approximated strategy selection of British university students which to some extent showed the influence of their L1transfer at sociopragmatic and pragmalinguistic levels.

Table 2 NS's and NNS's complaining supportive moves

\begin{tabular}{lllll}
\hline \multicolumn{1}{c}{ Supportive move } & \multicolumn{3}{c}{ NS } & \multicolumn{2}{c}{ NNS } \\
\hline Reviewing the situation & 1 & $2 \%$ & 5 & $5 \%$ \\
Explanation of purpose & 5 & $13 \%$ & 11 & $10 \%$ \\
Request for an explanation & 1 & $2 \%$ & 7 & $7 \%$ \\
Conveyance of a sense of urgency & 11 & $27 \%$ & 15 & $14 \%$ \\
Justification & 14 & $34 \%$ & 34 & $32 \%$ \\
Consequences & 2 & $5 \%$ & 6 & $6 \%$ \\
Disarmer & 7 & $17 \%$ & 27 & $26 \%$ \\
\hline \multicolumn{1}{c}{$\quad$ Total } & 41 & $100 \%$ & 105 & $100 \%$ \\
\hline
\end{tabular}

As far as social patterns of behaviour are concerned, an interesting observation can be found in the informal comments made by some of the Chinese participants, who underlined a different attitude towards the rules in Chinese and British societies. The British are perceived as more respectful of the rules and expecting the rules to be strictly observed, and therefore not inclined to review their position. This perceived guarantee of fairness was felt by some participants to decrease the necessity of issuing a complaint, while in China the more likely occurrence of nepotism seems to give more ground for complaining. This is the only indication that can be found in my data of a possible sociopragmatic violation of the native pattern of behaviour by a non native speaker.

Table 3 NS's and NNS's complaining directive acts

\begin{tabular}{|c|c|c|c|c|}
\hline Directive act & \multicolumn{2}{|c|}{ NS } & \multicolumn{2}{|c|}{ NNS } \\
\hline Request or suggestion for repair & 20 & $91 \%$ & 36 & $85.7 \%$ \\
\hline Request for forbearance & 1 & $4.5 \%$ & 2 & $4.7 \%$ \\
\hline Threat & 1 & $4.5 \%$ & 4 & $9.5 \%$ \\
\hline Total & 22 & $100 \%$ & 42 & $99.9 \%$ \\
\hline
\end{tabular}

The findings of the present study are consistent with Olshtain and Weinbach's results: contrary to the authors' expectations, in their investigation negligible differences were noticed in the choice of the complaint strategies among their groups of American English, British English and Hebrew L1 speakers, who seemed to prefer strategies with a medium degree of severity. The similarity of performance among the three culture groups was attributed to the much stronger impact of the situations chosen for their DCTs on the strategy choice, and it was observed that this impact was similar in all three cultures. The same frequency of use of complaint strategies between NNS with different L1 background and NS of American English was observed in Tanck’s study.

\section{Conclusion}

This project moved from the assumption that when people of different cultures have different norms about what type of politeness is required in a particular context, communication problems 
can easily arise, and aimed at investigating the possible sociopragmatic and pragmalinguistic differences in the performance of speech act of complaining in English as a first and a second language. Contrary to the expectations, and to the results of some previous investigations on the performance of complaints, the overall findings indicate that there were mainly similarities in the pragmatic behaviour of the native and non native speakers who participated in the research project, with a few minor differences.

\section{Acknowledgment}

This study was sponsored by China Scholarship Council, Social Science Planning Fund of Fujian Province (FJ2015C199) and Education Department Fund of Fujian Province (JAS150078).

\section{Reference}

[1]. C. Lee, "Mum, Sister Hit Me": Interlanguage Complaint Strategies of Cantonese Learners of English from Childhood to Their Teens. International Review of Pragmatics, vol.4, 2012. pp. 80-109.

[2]. Y.S., Chen, C.Y., Chen, and M.H. Chang, American and Chinese complaints: Strategy use from a cross-cultural perspective. Intercultural Pragmatics, vol. 8, 2011. pp. 253-275.

[3]. K. Bardovi-Harlig, "Documenting interlanguage development,” in Interlanguage: Forty years later. Z.Han, \& E. Tarone, Eds. Amsterdam: John Benjamins, 2014. pp. 134-154.

[4]. J. Austin, How to do things with words. Oxford: Clarendon Press, 1962.

[5]. J.R. Searle, Speech acts. Cambridge: Cambridge University Press, 1969.

[6]. J. Thomas, Meaning in interaction. London: Longman, 1995.

[7]. G. Leech, Principles of pragmatics. London: Longman, 1983.

[8]. P. Brown, and S.C. Levinson, Politeness. Cambridge: Cambridge University Press, 1987.

[9]. H.P. Grice, “Logic and conversation," in P. Cole, and J. Morgan, Pragmatics, Eds. vol 3. New York: Academic Press, 1975.

[10]. D. Boxer, "Studying speaking to inform second language learning," in Studying speaking to inform second language learning. D. Boxer and A. D. Cohen, Eds. Clevedon: Multilingual Matters, 2004.

[11]. E. Olshtain and L. Weinbach, "Interlanguage features of the speech act of complaining," in Interlanguage Pragmatics. G. Kasper and S. Blum-Kulka, Eds. Oxford: Oxford University Press, 1988.

[12]. A. Trosborg, Interlanguage pragmatics: requests, complaints and apologies. Berlin: Mouton de Gruyter, 1995.

[13]. B. Murphy and J. Neu, "My grade’s too low: the speech act set of complaining,” in ,Speech Acts Across Cultures : Challenges to Communication in a Second Language, S. Gass and J. Neu, Eds. Berlin: Mouton de Gruyter, 2006.

[14]. S. Tanck, Speech act sets of refusal and complaints: a comparison of native and non native English speakers' production, 2004. Retrieved on $5^{\text {th }}$ Jan 2016 from http://american.edu/tesol/workingpapers.htm

[15]. C. Roever, "Researching pragmatics," in Continuum Companion to Research Methods in Applied Linguistics, B. Paltridge and A. Phakiti. London: Continuum, 2010.

[16]. L.M. Beebe and H.Z. Waring, "The linguistic coding of pragmatic tone: adverbials as words that work," in Studying speaking to inform second language learning. D. Boxer and A. D. Cohen, Eds. Clevedon: Multilingual Matters, 2004. 